\title{
Obesity and impaired renal function: potential for lifestyle intervention?
}

\author{
Eva Corpeleijn · Stephan J. L. Bakker • \\ Ronald P. Stolk
}

Received: 7 April 2009/Accepted: 17 April 2009/Published online: 7 May 2009

(C) The Author(s) 2009. This article is published with open access at Springerlink.com

\begin{abstract}
Obesity is recently acknowledged as an important independent risk factor for kidney disease, in which epidemiological evidence played a crucial role. This risk is probably explained by intracellular lipid accumulation in the kidney. Lifestyle factors such as physical activity and diet play a role in the development of kidney disease in several stages: development of obesity and the metabolic syndrome, occurrence of obesity-related glomerulopathy, improvement of hemodialysis patients, and prevention of graft dysfunction and graft loss after renal transplantation. After the recent success of lifestyle intervention to prevent diabetes, further research is needed to show the effects of lifestyle changes to prevent and reduce obesity-related morbidity, including chronic kidney disease.
\end{abstract}

Keywords Kidney disease $\cdot$ Diabetes $\cdot$ Physical activity Diet

Impaired renal function is strongly related to cardiovascular disease and mortality [1]. One in every 200 adults suffers from chronic kidney disease, and with growing obesity epidemic, this is likely to increase. This means that since kidney disease takes a long time to develop, pre-clinical kidney

E. Corpeleijn · R. P. Stolk $(\varangle)$

Department of Epidemiology, University Medical Center

Groningen, University of Groningen, P.O. Box 30.001,

9700 RB Groningen, The Netherlands

e-mail: R.P.Stolk@epi.umcg.nl

\section{S. J. L. Bakker}

Department of Internal Medicine, University Medical Center Groningen, University of Groningen, Groningen, The Netherlands dysfunction is much more prevalent, and estimates in the general population range from 5 to $11 \%$ [2, 3]. From 1985 to 2000 , a tenfold increase in obesity-related glomerulopathy was found [4]. Other publications relate factors of the metabolic syndrome to renal function [5]. Insulin resistance and dyslipidemia are common factors in the early impairment of renal function [6,7]. Obesity is recently acknowledged as an important independent risk factor for kidney disease, in which epidemiological evidence played a crucial role. Obesity is related to various forms of kidney disease [8], including chronic renal failure [9] and end-stage renal disease (ESRD) $[10,11]$. These associations reported by Hsu et al. are presented in Table 1. In this paper we discuss this evidence and outline perspectives for future lifestyle intervention studies to protect the kidney and reduce related cardiovascular disease and mortality.

\section{Obesity as an independent factor}

A novel aspect in the field of renal epidemiology is that obesity is in itself an independent risk factor for the development of kidney disease. Obesity and the metabolic syndrome increase the risk for chronic kidney disease up to three- to fourfold [9, 12]. At most half of this obesityrelated risk is explained indirectly by traditional risk factors like hypertension and type 2 diabetes [9, 11, 12], leaving a large part unexplained.

Obesity is strongly related to hypertension and type 2 diabetes, and more in general to the metabolic syndrome. The metabolic syndrome describes the clustering of cardiovascular risk factors, including elevated blood pressure and impaired glucose metabolism, but also central obesity, elevated serum triglycerides and decreased serum HDLcholesterol. An important characteristic of the metabolic 
Table 1 Adjusted relative risk for end-stage renal disease (ESRD) by body mass index (BMI) in 320,000 US subjects

\begin{tabular}{lllc}
\hline BMI $\left(\mathrm{kg} / \mathrm{m}^{2}\right)$ & Odds ratio $^{\mathrm{a}}$ & $95 \% \mathrm{CI}$ & $\begin{array}{l}\text { Adjusted rate } \\
\text { per } 100,000 \text { person } \\
\text { years }(95 \% \mathrm{CI})^{\mathrm{b}}\end{array}$ \\
\hline $18.5-25.0$ & 1 & & $10(9-12)$ \\
$25.0-29.9$ & 1.87 & $1.64-2.14$ & $20(18-22)$ \\
$30.0-34.9$ & 3.57 & $3.05-4.18$ & $46(40-53)$ \\
$35.0-39.9$ & 6.12 & $4.97-7.54$ & $76(60-91)$ \\
$\geq 40.0$ & 7.07 & $5.37-9.31$ & $108(72-143)$ \\
\hline
\end{tabular}

Adapted from Hsu et al. [11]

a Adjusted for age, sex, race, education level, smoking status, history of myocardial infarction, serum cholesterol level, proteinuria, hematuria, and serum creatinine level and multiphasic health checkup period

b Adjusted for age, sex and race

syndrome is the excess lipid accumulation in organs other than adipose tissue, e.g., in liver, skeletal muscle, pancreas and possibly in the kidney.

Epidemiological studies have played an important role to identify the metabolic syndrome as a risk factor for impaired kidney function. In 10,096 nondiabetic participants from the Atherosclerosis Risk in Communities (ARIC) study who had normal baseline kidney function, 691 (7\%) participants developed chronic kidney disease (CKD) after 9 years of follow-up [12]. For subjects with the metabolic syndrome, the multivariable adjusted odds ratio (OR) of developing CKD was 1.43 (95\% CI 1.181.73). After adjusting for the subsequent development of diabetes and hypertension during the 9 years follow-up, the OR was 1.24 (95\% CI 1.01-1.51). A case-control study showed that overweight $\left(\mathrm{BMI} \geq 25 \mathrm{~kg} / \mathrm{m}^{2}\right)$ at age 20 was associated with a significant threefold excess risk for chronic renal failure, relative to BMI $<25$ [9]. This risk was also threefold in individuals who were overweight at age 20 but did not develop hypertension or diabetes.

\section{Assessment of kidney disease}

In the ARIC study described above, incident CKD was defined as an estimated GFR (eGFR) $<60 \mathrm{ml} / \mathrm{min}$ per $1.73 \mathrm{~m}^{2}$ after 9 years among those with an eGFR $\geq 60 \mathrm{ml} /$ min per $1.73 \mathrm{~m}^{2}$ at baseline [12]. The eGFR is usually calculated with abbreviated Modification of Diet in Renal Disease (MDRD) study equation [13], derived from serum creatinine, age, sex and race. Serum creatinine can thus be used as a plasma markers for kidney function, but is also directly related to muscle mass and physical activity [14]. This may overestimate kidney function in physically inactive individuals, and thereby underestimate the true effect of obesity. Other studies report CKD or ESRD from medical records. However, these endpoints do not represent early kidney dysfunction due to competition with cardiovascular death. Additional measurements of urinary albumin may largely improve the identification of individuals at increased risk for progressive renal disease [15].

\section{Pathophysiology}

Already in the 70s it was reported that obesity is related to increased proteinuria [16]. Recently, an obesity-related form of glomerulopathy was described [4]. This obesityrelated glomerulopathy was characterized by fewer lesions of segmental sclerosis, more glomerulomegaly, and less extensive foot process effacement (impaired glomerular basement membrane integrity) than patients with classical idiopathic focal segmental glomerulosclerosis.

Studies in mice show that intracellular lipid accumulation in the kidney plays a role in high-fat diet induced albuminuria, glomerular and tubular changes [17] and in the age-related decline in kidney function, including albuminuria and glomerulosclerosis [18]. The issue of lipotoxicity has become especially relevant in the current obesogenic society and the widely spread prevalence of a high total and saturated fat intake.

Peripheral insulin resistance leads to hyperinsulinemia, necessary to keep blood glucose levels within normal limits. Such hyperinsulinemia may lead to overstimulation in various other tissues that seem to preserve their normal responsiveness to insulin, like the kidney [19]. This can have harmful consequences. Animal experiments show that excess insulin is associated with decreased endothelial production of nitric oxide and increased oxidative stress. Furthermore, excess insulin may promote the proliferation of renal cells via growth factors and stimulation of growth factor receptors [20]. Another mechanism that has attracted renewed interest in the association between obesity and altered renal hemodynamics. A number of early studies in healthy subjects-performed in times that obesity was not yet considered a risk factor for chronic kidney diseaseshow that insulin may have detrimental effects on renal hemodynamics (blood circulation in the kidney) [21, 22]. Nowadays it is known that also in the non-obese range (BMI between 23 and $30 \mathrm{~kg} / \mathrm{m}^{2}$ ), obesity is related to hemodynamic changes [23]. Hemodynamic changes are related to hyperfiltration and increased intraglomerular pressure, podocyte injury, albuminuria (of FFA-rich albumin), and tubular cell injury. Several obesity related factors are involved in hemodynamic changes, including hormonal changes in the renin-angiotensin system, increased sympathetic tone, and potentially increased circulating FFA and leptin [24]. 


\section{Lifestyle}

Lifestyle factors such as physical activity [25] and diet [26, 27] are important modifiable factors for insulin resistance, and have been associated with the risk of kidney disease [28]. In the second National Health and Nutrition Examination Survey (NHANES II, $n=9,082$ ), the risk of chronic kidney disease was related to physical inactivity both with and without adjustment for age, sex, race and body-mass index [28]. The adjusted relative risk (RR) of inactive versus very active was 2.2 (CI 1.3-3.8). This risk was comparable to the RR in smokers of more than 20 cigarettes a day versus never smokers ( $\mathrm{RR}=2.3$; CI 1.3-4.2).

Lifestyle can play a role in the development of kidney disease in several stages, as indicated in the Fig. 1. Obviously, lifestyle modulates the development of obesity and the metabolic syndrome. Lifestyle contributes to the development of type 2 diabetes and hypertension in several ways, including energy intake, intake of saturated fat, salt intake, and physical activity. Less clear is whether lifestyle is related to the development of diabetic nephropathy, once patients have developed type 2 diabetes, but it is very likely that it is of influence on the development of obesity-related glomerulopathy. After renal transplantation, the metabolic syndrome is a prominent risk factor for post-transplantation diabetes mellitus, chronic graft dysfunction, graft loss, and patient death in renal transplant recipients [29]. Behavioural changes to prevent weight gain may counteract the post-transplant development of the metabolic syndrome and thereby improve renal graft function and survival on the long-term [30, 31].

A classical nutritional factor in renal function is salt intake [32]. The effect of salt on renal function is related to both high blood pressure and to a direct effect on renal function, i.e., hemodynamic changes. The effect of sodium intake on cardiovascular disease in Western societies remains to be established, but urinary sodium/potassium intake may be related to all-cause mortality in specific groups of overweight subjects [33]. An in-depth review on dietary salt intake and renal function reproduces that variations in salt consumption are directly correlated with albuminuria. Furthermore, an increase in salt consumption is associated with an acute increase in glomerular filtration rate, whereas a reduction in salt consumption may slow the rate of renal function loss [34].

Likewise, many other lifestyle changes may be beneficial. In nondialysis CKD, exercise can decrease microalbuminuria, protect from oxidative stress, reduce inflammation, help to maintain body weight, increase IGF-1 and increase renal function (for review by Moinuddin and Leehey see [35]). In summary, exercise in hemodialysis patients has been reported to enhance insulin sensitivity, improve lipid profile, increase hemoglobin, improve IGF-1 status, increase muscle strength, decrease blood pressure, increase physical functionality and improve quality of life. Combined aerobic exercise and resistance training during dialysis improves muscle strength, work output, cardiac fitness, and possibly dialysis adequacy [36]. Also the maintenance or reduction on body weight will be beneficial. Obesity in the early stages of renal disease, and an increase in BMI after renal transplantation are important risk factors for cardiovascular disease and decline in renal function [37]. Very little is known about other nutritional factors such as a high saturated fat intake, low fibre intake and glycemic index/glycemic load of the food.
Fig. 1 Lifestyle can play a role in the development of kidney disease in several stages

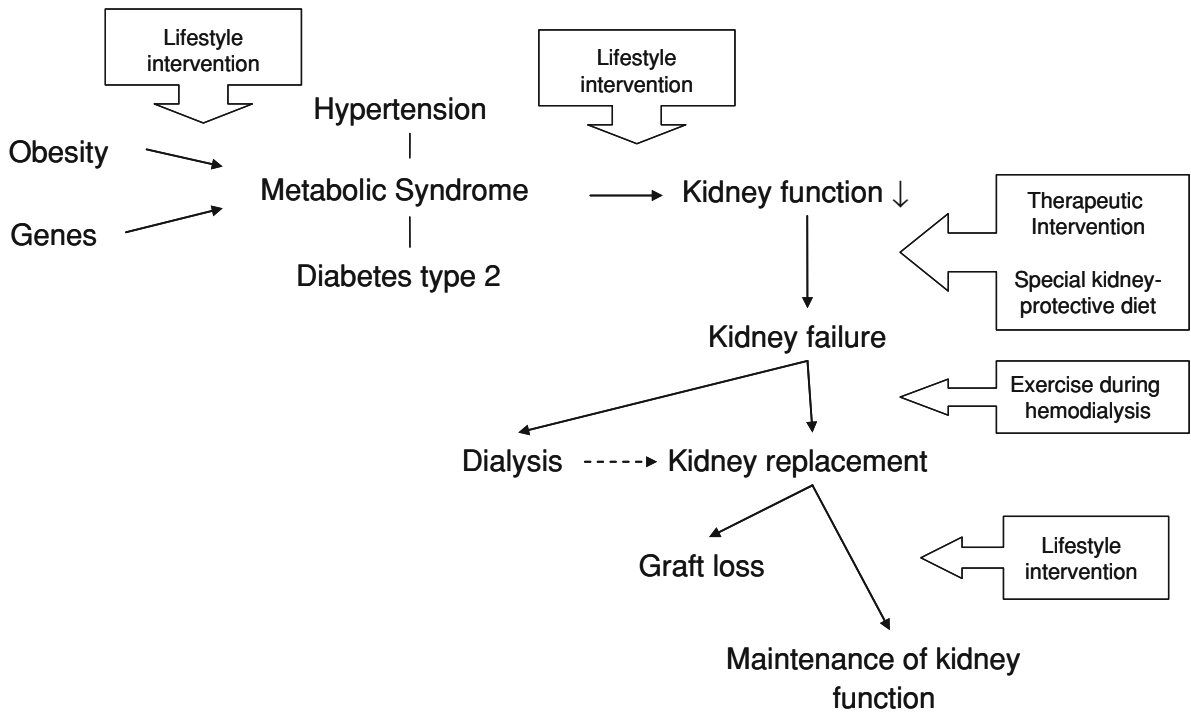

Springer 


\section{Perspectives}

Pharmacological intervention to correct individual components of the metabolic syndrome (including high blood lipids, high cholesterol and elevated blood pressure) has been proven beneficial to retard renal function decline. Lifestyle intervention is a powerful tool to prevent or delay progression from a healthy or prediabetic state to type 2 diabetes [38-41], with lifestyle being at least as effective as pharmaceutical intervention [39, 42, 43]. Despite the notification of lifestyle changes in the guidelines for treatment of end-stage renal disease, the prescription of physical activity or other lifestyle changes has been severely hampered, among others by lack of convincing evidence. The recent success of lifestyle changes in diabetes research has improved the support for lifestyle changes as a tool to prevent and reduce obesity-related morbidity, including chronic kidney disease.

The publication of the Kidney Disease Outcomes Quality Initiative (K/DOQI) guidelines for the evaluation, classification, and stratification of chronic kidney disease in 2002 [44] has raised awareness of chronic kidney disease and greatly stimulated epidemiological research.

However, there are a number of unanswered questions in the relation between lifestyle and improvement of renal function. Whether lifestyle changes that benefit diabetes will also benefit kidney function is unknown, but interesting from a practical as well as an etiological point of view. The role of dietary fats is unknown but the substitution of saturated fats for unsaturated fats could have great potential to prevent kidney disease as well as related cardiovascular disease. Weight loss, or the prevention of weight gain, is a very promising strategy. Weight loss has been the centre of a lively debate, since in end-stage renal disease, an elevated BMI is associated with a higher life expectancy [37]. With the need for dialysis, a catabolic process with muscular atrophy and loss of stored fat begins. On the other hand, obesity in the early stages of renal disease, and an increase in BMI after renal transplantation are important risk factors for cardiovascular disease and a decline in renal function and should be prevented. It is very likely that nutritional risk factors for cardiovascular disease, such as a high saturated fat intake and low fibre intake are also relevant for renal function, and certainly relevant in renal patients due to their increased CVD risk.

At the same time, it is still unclear to what extent preclinical kidney dysfunction is related to cardiovascular events, and whether kidney-specific factors may increase CVD risk in the general population. Also the relationship between obesity-related factors such as inflammatory parameters and early development of renal dysfunction deserves attention. Decently designed epidemiological and intervention studies are needed to fill these gaps in our knowledge. A logistic obstacle in large scale studies might be the collection of $24 \mathrm{~h}$ urine samples, which is necessary to calculate creatinine clearance and quantitatively assess renal function. With the awareness that early renal dysfunction is relatively common, projects like the recently started LifeLines cohort study now include urine sampling and demonstrate that this is feasible in daily epidemiological practice [45]. In addition, especially in the current obesogenic society, we need effective and tailored lifestyle programs to prevent early renal dysfunction and related cardiovascular disease, as well as to improve the long-term success of renal transplantation.

Acknowledgments The authors thank Prof. G. J. Navis for sharing her knowledge about obesity and renal function.

Open Access This article is distributed under the terms of the Creative Commons Attribution Noncommercial License which permits any noncommercial use, distribution, and reproduction in any medium, provided the original author(s) and source are credited.

\section{References}

1. Levey AS, Beto JA, Coronado BE, Eknoyan G, Foley RN, Kasiske BL, et al. Controlling the epidemic of cardiovascular disease in chronic renal disease: what do we know? What do we need to learn? Where do we go from here? National kidney foundation task force on cardiovascular disease. Am J Kidney Dis. 1998;32(5):853-906. doi:10.1016/S0272-6386(98)70145-3.

2. de Zeeuw D, Hillege HL, de Jong PE. The kidney, a cardiovascular risk marker, and a new target for therapy. Kidney Int Suppl. 2005;68:S25-9. doi:10.1111/j.1523-1755.2005.09805.x.

3. Coresh J, Astor BC, Greene T, Eknoyan G, Levey AS. Prevalence of chronic kidney disease and decreased kidney function in the adult US population: third national health and nutrition examination survey. Am J Kidney Dis. 2003;41(1):1-12. doi: 10.1053/ajkd.2003.50007.

4. Kambham N, Markowitz GS, Valeri AM, Lin J, D'Agati VD. Obesity-related glomerulopathy: an emerging epidemic. Kidney Int. 2001;59(4):1498-509. doi:10.1046/j.1523-1755.2001.05900 41498.x.

5. Bakker SJ, Gansevoort RT, de Zeeuw D. Metabolic syndrome: a fata morgana? Nephrol Dial Transplant. 2007;22(1):15-20. doi: 10.1093/ndt/gfl581.

6. Kronborg J, Jenssen T, Njolstad I, Toft I, Eriksen BO. Metabolic risk factors associated with serum creatinine in a non-diabetic population. Eur J Epidemiol. 2007;22(10):707-13. doi:10.1007/ s10654-007-9164-8.

7. Rathmann W, Haastert B, Icks A, Giani G, Roseman JM. Tenyear change in serum uric acid and its relation to changes in other metabolic risk factors in young black and white adults: the CARDIA study. Eur J Epidemiol. 2007;22(7):439-45. doi: 10.1007/s10654-007-9132-3.

8. Wang Y, Chen X, Song Y, Caballero B, Cheskin LJ. Association between obesity and kidney disease: a systematic review and meta-analysis. Kidney Int. 2008;73(1):19-33. doi:10.1038/sj.ki. 5002586.

9. Ejerblad E, Fored CM, Lindblad P, Fryzek J, McLaughlin JK, Nyren O. Obesity and risk for chronic renal failure. J Am Soc Nephrol. 2006;17(6):1695-702. doi:10.1681/ASN.2005060638. 
10. Iseki K, Ikemiya Y, Kinjo K, Inoue T, Iseki C, Takishita S. Body mass index and the risk of development of end-stage renal disease in a screened cohort. Kidney Int. 2004;65(5):1870-6. doi: 10.1111/j.1523-1755.2004.00582.x.

11. Hsu CY, McCulloch CE, Iribarren C, Darbinian J, Go AS. Body mass index and risk for end-stage renal disease. Ann Intern Med. 2006;144(1):21-8.

12. Kurella M, Lo JC, Chertow GM. Metabolic syndrome and the risk for chronic kidney disease among nondiabetic adults. J Am Soc Nephrol. 2005;16(7):2134-40. doi:10.1681/ASN.200501 0106.

13. Levey AS, Bosch JP, Lewis JB, Greene T, Rogers N, Roth D. A more accurate method to estimate glomerular filtration rate from serum creatinine: a new prediction equation. Modification of diet in renal disease study group. Ann Intern Med. 1999;130(6):461-70.

14. Oterdoom LH, van Ree RM, de Vries AP, Gansevoort RT, Schouten JP, van Son WJ, et al. Urinary creatinine excretion reflecting muscle mass is a predictor of mortality and graft loss in renal transplant recipients. Transplantation. 2008;86(3):391-8. doi:10.1097/TP.0b013e3181788aea.

15. van der Velde M, Halbesma N, de Charro FT, Bakker SJ, de Zeeuw D, de Jong PE, et al. Screening for albuminuria identifies individuals at increased renal risk. J Am Soc Nephrol. 2009 Feb 11.

16. Weisinger JR, Kempson RL, Eldridge FL, Swenson RS. The nephrotic syndrome: a complication of massive obesity. Ann Intern Med. 1974;81(4):440-7.

17. Deji N, Kume S, Araki SI, Soumura M, Sugimoto T, Isshiki K, et al. Structural and functional changes in the kidneys of high-fat diet-induced obese mice. Am J Physiol Renal Physiol. 2008 Oct 29.

18. Jiang T, Liebman SE, Lucia MS, Li J, Levi M. Role of altered renal lipid metabolism and the sterol regulatory element binding proteins in the pathogenesis of age-related renal disease. Kidney Int. 2005;68(6):2608-20. doi:10.1111/j.1523-1755.2005.00733.x.

19. Sarafidis PA, Bakris GL. The antinatriuretic effect of insulin: an unappreciated mechanism for hypertension associated with insulin resistance? Am J Nephrol. 2007;27(1):44-54. doi: 10.1159/000098955.

20. Sarafidis PA, Ruilope LM. Insulin resistance, hyperinsulinemia, and renal injury: mechanisms and implications. Am J Nephrol. 2006;26(3):232-44. doi:10.1159/000093632.

21. ter Maaten JC, Bakker SJ, Serne EH, ter Wee PM, Donker AJ, Gans RO. Insulin's acute effects on glomerular filtration rate correlate with insulin sensitivity whereas insulin's acute effects on proximal tubular sodium reabsorption correlation with salt sensitivity in normal subjects. Nephrol Dial Transplant. 1999;14(10):2357-63. doi:10.1093/ndt/14.10.2357.

22. ter Maaten JC, Bakker SJ, Serne EH, Moshage HJ, Donker AJ, Gans RO. Insulin-mediated increases in renal plasma flow are impaired in insulin-resistant normal subjects. Eur J Clin Invest. 2000;30(12):1090-8. doi:10.1046/j.1365-2362.2000.00749.x.

23. Bosma RJ, van der Heide JJ, Oosterop EJ, de Jong PE, Navis G. Body mass index is associated with altered renal hemodynamics in non-obese healthy subjects. Kidney Int. 2004;65(1):259-65. doi:10.1111/j.1523-1755.2004.00351.x.

24. Bosma RJ, Krikken JA, van der Heide HJJ, de Jong PE, Navis GJ. Obesity and renal hemodynamics. Contrib Nephrol. 2006;151: 184-202. doi:10.1159/000095329.

25. Bruce CR, Hawley JA. Improvements in insulin resistance with aerobic exercise training: a lipocentric approach. Med Sci Sports Exerc. 2004;36(7):1196-201.

26. Riccardi G, Giacco R, Rivellese AA. Dietary fat, insulin sensitivity and the metabolic syndrome. Clin Nutr. 2004;23(4):44756. doi:10.1016/j.clnu.2004.02.006.
27. Corpeleijn E, Feskens EJ, Jansen EH, Mensink M, Saris WH, de Bruin TW, et al. Improvements in glucose tolerance and insulin sensitivity after lifestyle intervention are related to changes in serum fatty acid profile and desaturase activities: the SLIM study. Diabetologia. 2006;49(10):2392-401. doi:10.1007/s00125-0060383-4.

28. Stengel B, Tarver-Carr ME, Powe NR, Eberhardt MS, Brancati FL. Lifestyle factors, obesity and the risk of chronic kidney disease. Epidemiology. 2003;14(4):479-87.

29. Porrini E, Delgado P, Bigo C, Alvarez A, Cobo M, Checa MD, et al. Impact of metabolic syndrome on graft function and survival after cadaveric renal transplantation. Am J Kidney Dis. 2006;48(1):134-42. doi:10.1053/j.ajkd.2006.04.078.

30. Bosma RJ, Kwakernaak AJ, van der Heide JJ, de Jong PE, Navis GJ. Body mass index and glomerular hyperfiltration in renal transplant recipients: cross-sectional analysis and long-term impact. Am J Transplant. 2007;7(3):645-52. doi:10.1111/j.16006143.2006.01672.x

31. Jezior D, Krajewska M, Madziarska K, Regulska-Ilow B, Ilow R, Janczak D, et al. Weight reduction in renal transplant recipients program: the first successes. Transplant Proc. 2007;39(9):276971. doi:10.1016/j.transproceed.2007.08.055.

32. de Francisco AL, Fresnedo GF, Palomar R, Pinera C, Arias M. The renal benefits of a healthy lifestyle. Kidney Int Suppl. 2005;68:S2-6. doi:10.1111/j.1523-1755.2005.09901.x.

33. Geleijnse JM, Witteman JC, Stijnen T, Kloos MW, Hofman A, Grobbee DE. Sodium and potassium intake and risk of cardiovascular events and all-cause mortality: the Rotterdam study. Eur J Epidemiol. 2007;22(11):763-70. doi:10.1007/s10654-0079186-2.

34. Jones-Burton C, Mishra SI, Fink JC, Brown J, Gossa W, Bakris GL, et al. An in-depth review of the evidence linking dietary salt intake and progression of chronic kidney disease. Am J Nephrol. 2006;26(3):268-75. doi:10.1159/000093833.

35. Moinuddin I, Leehey DJ. A comparison of aerobic exercise and resistance training in patients with and without chronic kidney disease. Adv Chronic Kidney Dis. 2008;15(1):83-96. doi: 10.1053/j.ackd.2007.10.004.

36. van Vilsteren MC, de Greef MH, Huisman RM. The effects of a low-to-moderate intensity pre-conditioning exercise programme linked with exercise counselling for sedentary haemodialysis patients in The Netherlands: results of a randomized clinical trial. Nephrol Dial Transplant. 2005;20(1):141-6. doi:10.1093/ndt/ gfh560.

37. Kramer H, Luke A. Obesity and kidney disease: a big dilemma. Curr Opin Nephrol Hypertens. 2007;16(3):237-41. doi:10.1097/ MNH.0b013e32803578e4.

38. Roumen C, Corpeleijn E, Feskens EJ, Mensink M, Saris WH, Blaak EE. Impact of 3 year lifestyle intervention on postprandial glucose metabolism: the SLIM study. Diabet Med. 2008;25(5): 597-605. doi:10.1111/j.1464-5491.2008.02417.x.

39. Knowler WC, Barrett-Connor E, Fowler SE, Hamman RF, Lachin JM, Walker EA, et al. Reduction in the incidence of type 2 diabetes with lifestyle intervention or metformin. N Engl J Med. 2002;346(6):393-403. doi:10.1056/NEJMoa012512.

40. Lindstrom J, Ilanne-Parikka P, Peltonen M, Aunola S, Eriksson JG, Hemio K, et al. Sustained reduction in the incidence of type 2 diabetes by lifestyle intervention: follow-up of the Finnish diabetes prevention study. Lancet. 2006;368(9548):1673-9. doi: 10.1016/S0140-6736(06)69701-8.

41. Mensink M, Corpeleijn E, Feskens EJ, Kruijshoop M, Saris WH, de Bruin TW, et al. Study on lifestyle-intervention and impaired glucose tolerance Maastricht (SLIM): design and screening results. Diabetes Res Clin Pract. 2003;61(1):49-58. doi:10.1016/ S0168-8227(03)00067-6. 
42. Gillies CL, Abrams KR, Lambert PC, Cooper NJ, Sutton AJ, Hsu RT, et al. Pharmacological and lifestyle interventions to prevent or delay type 2 diabetes in people with impaired glucose tolerance: systematic review and meta-analysis. BMJ. 2007;334 (7588):299. doi:10.1136/bmj.39063.689375.55.

43. Roumen C, Blaak EE, Corpeleijn E. Lifestyle intervention in the prevention of diabetes: determinants of success for future implementation. Nutr Rev. 2009;67(3):132-46.
44. National Kidney Foundation. K/DOQI clinical practice guidelines for chronic kidney disease: evaluation, classification, and stratification. Am J Kidney Dis. 2002;39 Suppl 1(2):S1-266.

45. Stolk RP, Rosmalen JG, Postma DS, de Boer RA, Navis G, Slaets JP, et al. Universal risk factors for multifactorial diseases: lifelines: a three-generation population-based study. Eur J Epidemiol. 2008;23(1):67-74. doi:10.1007/s10654-007-9204-4. 